\title{
Performance analysis of a mini-thermoelectric engine for the generation of electricity
}

\author{
Nazdar A. Qadr, Saadia W. Muhammad, and Fahmi F. Muhammad* \\ Soft Materials and Devices Laboratory, Department of Physics, Faculty of Science and Health, \\ Koya University, Koya, Kurdistan Region, Iraq \\ *Corresponding author email: fahmi.fariq@koyauniversity.org; fahmi982@gmail.com \\ Tel: +9647701935331
}

Keywords: Stirling engine, thermoelectric, performance, electric power.

\begin{abstract}
In this research work a small thermal engine was utilized for generation of electrical energy and its operation was analyzed in terms of the output performance with various external load resistances and different flywheel rotations. It was seen from the results that with increase of the external load there is a less considerable increase in voltage. It has been observed that by an increasing the external load from $100 \Omega$ to about $2000 \Omega$, a rapid decrease in the output power is occurred. However, beyond a specific value of about $2000 \Omega$ the decrease in the electrical power is relatively small. It was obvious from the results of output voltage, current and power with respect to the increase in hot air temperature $\left(\mathrm{T}_{1}\right)$ that these physical quantities are increased at a constant rate for specific range of temperatures, from $185{ }^{\circ} \mathrm{C}$ to about $240{ }^{\circ} \mathrm{C}$. It was worth mentioning that at higher temperatures the rate of increase in output voltage was reduced, implying that the expansion rate of hot air is getting saturated and the rotating speed of the flywheel reached its maximum capability to generate electricity.
\end{abstract}

\section{Introduction}

The impacts of fossil fuel on the environment, especially the global warming and the harmful effects of carbon emissions have created a new demand for clean and sustainable energy sources like wind, sea, solar, biomass, and geothermal powers [1]. Thermoelectric power of a material is a measure of the magnitude of an induced thermoelectric voltage in response to a temperature difference across that material [2]. The phenomenon quantified by thermo-power is called the Seeback effect [3], where the thermal energy is directly converted into electrical energy due to the change in temperature degree within the material. Another way of generating electricity, which is focused on in the current work, is to indirectly convert thermal energy into electricity. This process can be accomplished by using Stirling engine [4-6], in which the conversion of thermal power into mechanical power is realized and then used to rotate small generators [7], thereby producing a desirable electrical power. The Stirling engine is a heat engine operating by cyclic compression and expansion of air or other gases at different temperature levels such that there is a net conversion of heat energy to electrical energy. The Stirling engine is known for its high efficiency, quiet operation, and the ease with which it can use almost any heat source. This compatibility with alternative and renewable energy sources has become increasingly significant as the price of conventional fuels rises, and also in light of concerns such as peak oil and climate change. The initiated thermal source can be obtained from either biomass or sun-heat energy. M. Zamani et al. [8] utilized thermal energy storage for reducing battery bank size of hybrid (wind-pv) systems in hot climates, while L.V. Guoqiang et al. [9] investigated energy and exergy (the maximum possible work during a process) analysis for a $300 \mathrm{MW}$ thermal power plant system. Interestingly, Noble et al. [10] carried out a research on selecting materials for Stirling engine heater head. They proposed a wide range of materials for the heater head and tubes, which they have been evaluated based on materials strength and their effects on engine efficiency, reliability and the cost. Further study was done by Nakis and Christopher [11] to model and analyze Stirling engine dynamic system, basically 
its thermo-mechanical system. The studies aimed at analyzing key parameters of the system and quantifying the results.

In order to realize a free piston Stirling engine system, M.A. White et al. [12] performed a preliminary test on a free-piston Stirling engine technology. The long-term objective was to develop a power system with an efficiency exceeding $20 \%$ that can function with a high degree of reliability for up to 15 years. As such, the concept of thermal energy conversion to electricity by means of Stirling engines has received considerable attention. Therefore, the performance analysis of a mini-thermoelectric system in terms of thermal energy conversion and electrical power generation at various loads and different flywheel rotations will be investigated throughout this research work. The analysis will be advantageous for deeper understanding of the generator function and to give an overall idea in designing and fabrication of this generator for larger power applications.

\section{Materials and methods}

Stirling engine is a heat engine operating by cyclic compression and expansion of air or other gas, the working fluid, at different temperature levels such that there is a net conversion of heat energy to mechanical energy. Figure 1 shows the illustration of a small Striling engine that was utilized in the current research work.

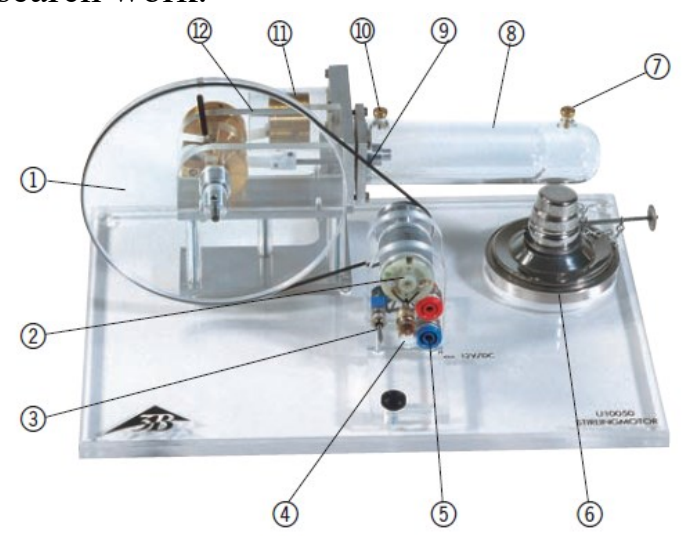
(1) Flywheel with marking for speed determination
(2) Motor-generator unit with 2-stage pulley
(3) Switch
(4) Bulb
(5) 4-mm safety plugs
(6) Alcohol burner
(7) Temperature measurement connector 1
(8) Displacement piston
(9) Capped hose connection for pressure measurements
(10) Temperature measurement connector 2
(11) Working piston
(12) Threaded rod M3 (connected with the working piston)

Figure 1: Illustration of a mini-Striling engine sued in the current study.

The alcohol burner served as an energy source. An electric motor, connected to the flywheel via a belt, acts as a generator to supply a voltage to a bulb or another loads via the output jacks. Below are the important parameters with regard to the heat engine [13]:

- Speed without a load: Approximately 1000 RPM

- Speed with a generator as the load: Approximately 650 RPM

- Generator voltage: Approximately 6 V DC

The output jacks of the heat engine, where electrical energy can be transferred from the motor into an external load, was connected to a variable resistor ranging from 100 to $11 \mathrm{k} \Omega$. The variable resistor was used to represent a variable load, thereby estimating the electrical energy delivered instantaneously upon heating the head cylinder. To measure the current passes through the load and voltage drop produced on the external load, digital multi-meters were used. Two thermometers were also utilized to measure each of the hot side temperature $\left(\mathrm{T}_{1}\right)$ inside the closed hot air cylinder and the cooler side temperature $\left(\mathrm{T}_{2}\right)$ in Celsius degrees. The temperature gradient between the hot and cold side regions $\left(T_{1}-T_{2}\right)$ has given us plentiful information regarding the way of transferring heat energy into the electrical energy through the hot air. This was basically done by expansion of the hot air within the closed cylinder making the piston to expand towards the colder region. As such, the heat energy is transferred into the mechanical energy, which in turn acts upon rotating the electrical motor and hence delivering the electrical energy to the external load. 
The data collections were carried out for two sets of experiments, as shown in Figure 2. First, the flywheel rotation in rotation per minute (RPM) was tried to be fixed at specific values then the external load has been varied in steps from 100 to $11 \mathrm{k} \Omega$. As such, for two situations, where the rotation was fixed at about 122 RPM and 130 RPM, each of current passing through the load, voltage, hot temperature $\left(T_{1}\right)$ and cold temperature $\left(T_{2}\right)$ were measured. Moreover, the output power $(\mathrm{P}=\mathrm{I} . \mathrm{V})$ and temperature gradient $\left(\mathrm{T}_{1}-\mathrm{T}_{2}\right)$ were recorded. Additioanly, the external load was fixed at $1 \mathrm{k} \Omega$ while the flywheel rotation was instantaneously varied by increasing the rate of burning of alcohol, and then all the above physical quantities were measured again. From the collected data, several graphs have been produced to analyze and understand the performance of the utilized thermal electric engine.

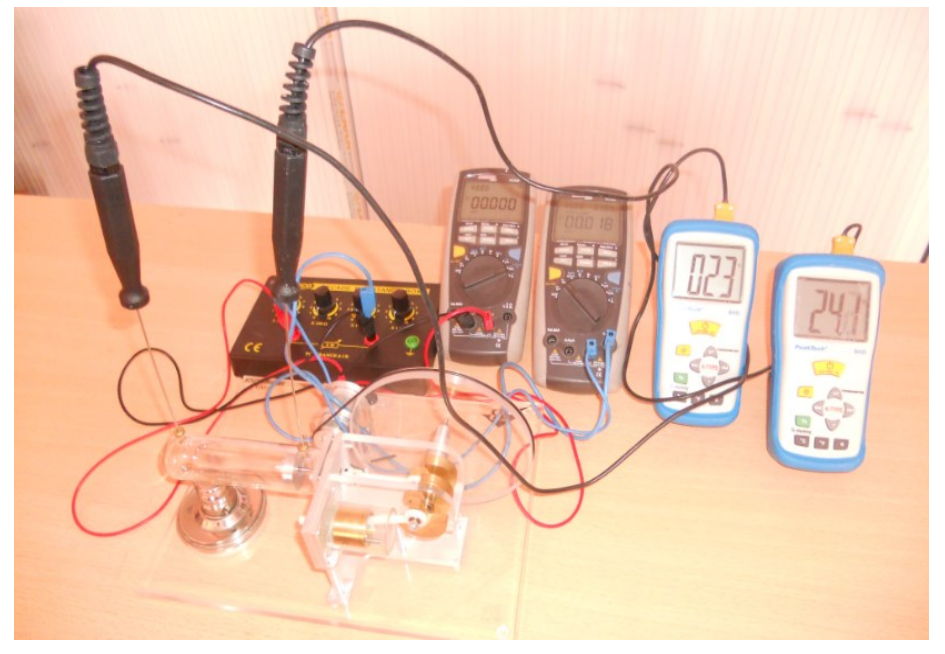

Figure 2: Experimental setup to analyze a mini-thermoelectric generator.

\section{Results and discussion}

Figure 3 shows the change in the output voltage with increase in the external load for the flywheel speed of 122 RPM. It is clear from the curve that with increase of the external load resistance there is a less considerable increase in voltage. Based on the Ohm's law however there should be sharp increase in voltage with increase of the resistor load, but its less and moderate increase can be related to the impedance matching between the load and the electric motor. This is because the electrical motor will provide maximum current flows only when the external load resistor is equal to the internal resistance of the motor.

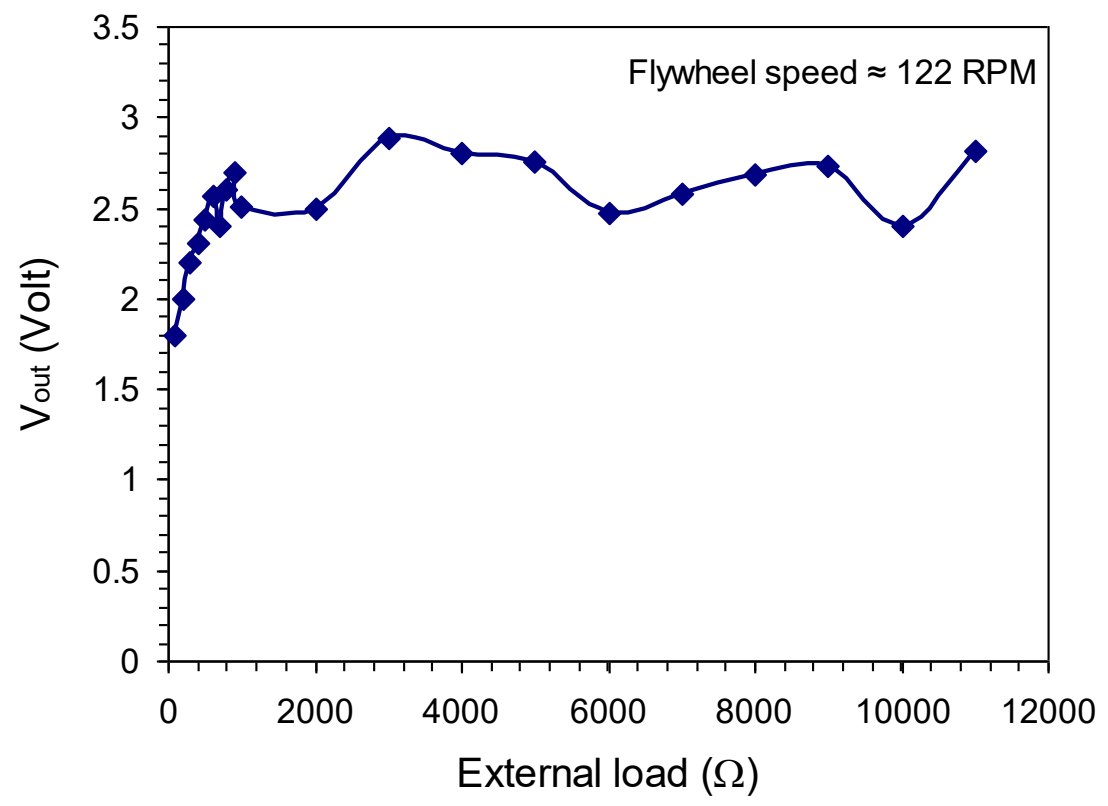

Figure 3: Plot of external load versus output voltage for flywheel speed 122 rpm. 
Figure 4 shows the change in the output power with increase in the external load for the flywheel speed of about 122 RPM. One can observe that by increasing the external load from $100 \Omega$ to about $2000 \Omega$, a rapid decrease in the output power was occurred. However, beyond a specific value of about $2000 \Omega$, the decrease in the electrical power was relatively small. This was ascribed to the decrease in the current flowing through the external load as the more decrease at higher resistance acts upon deteriorate the rotation of the flywheel. The change in the rotation of the flywheel can be due to the generation of the electromotive force within the electrical motor connected to the load.

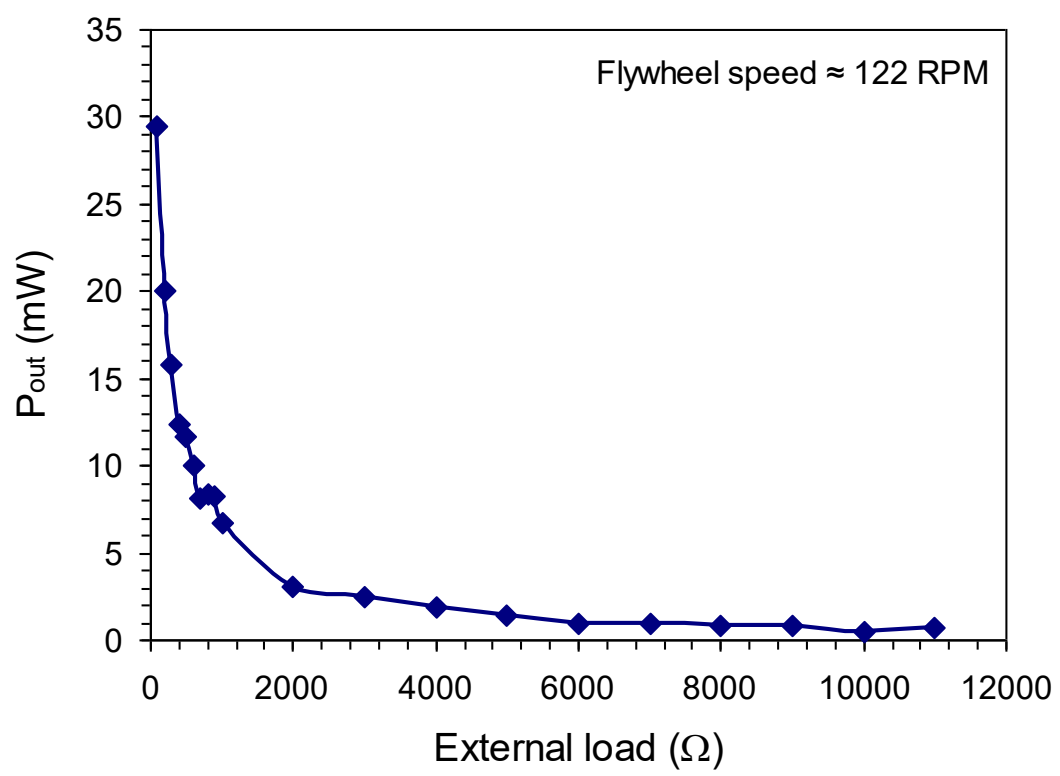

Figure 4: Plot of the external load versus output power.

Figure 5 shows the change in the cold region temperature $\left(T_{2}\right)$ with increase in the output power for the flywheel speed of about 122 RPM. It was seen that upon increase in the output power the temperature $\mathrm{T}_{2}$ dropped down more and more. This is a good indication of temperature gradient with respect of the power delivered to the load as the more power transferring means that the cylinders are moving efficiently to make the hot air cooled down easily. The reverse situation is also true to give the agreement that is in accordance with the load matching principle, as at lower output power (high external load) the temperature $\mathrm{T}_{2}$ somewhat decreases.

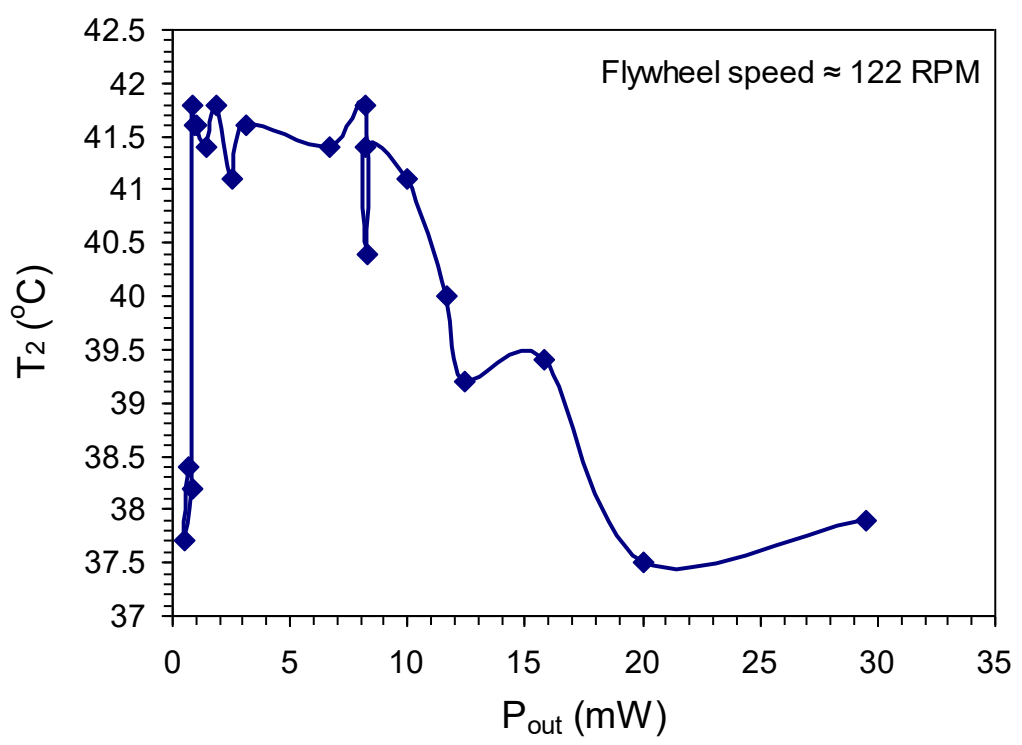

Figure 5: Relation between the output power and the cold region temperature $\left(T_{2}\right)$. 
Figure 6 shows the change in the temperature gradient between the hot air and cold air regions $\left(\mathrm{T}_{1}-\mathrm{T}_{2}\right)$ with increase in the external load for the flywheel speed of about $122 \mathrm{RPM}$. The relatively constant temperature gradient at various external load resistances is a right indication to the smooth and stable operation of the thermo electric engine for the production of electrical energy. There may be another indication for that the system was operated in thermally equilibrium with the surrounding.



Figure 6: Relation between the external load and the gradient in temperature $\left(T_{1}-T_{2}\right)$.

The same trends of the relation between the output power and the cold region temperature $\left(T_{2}\right)$ as well as relation between the external load and the gradient in temperature $\left(T_{1}-T_{2}\right)$ can be seen for the flywheel speed of about 130 RPM as shown in Figure 7 and 8.

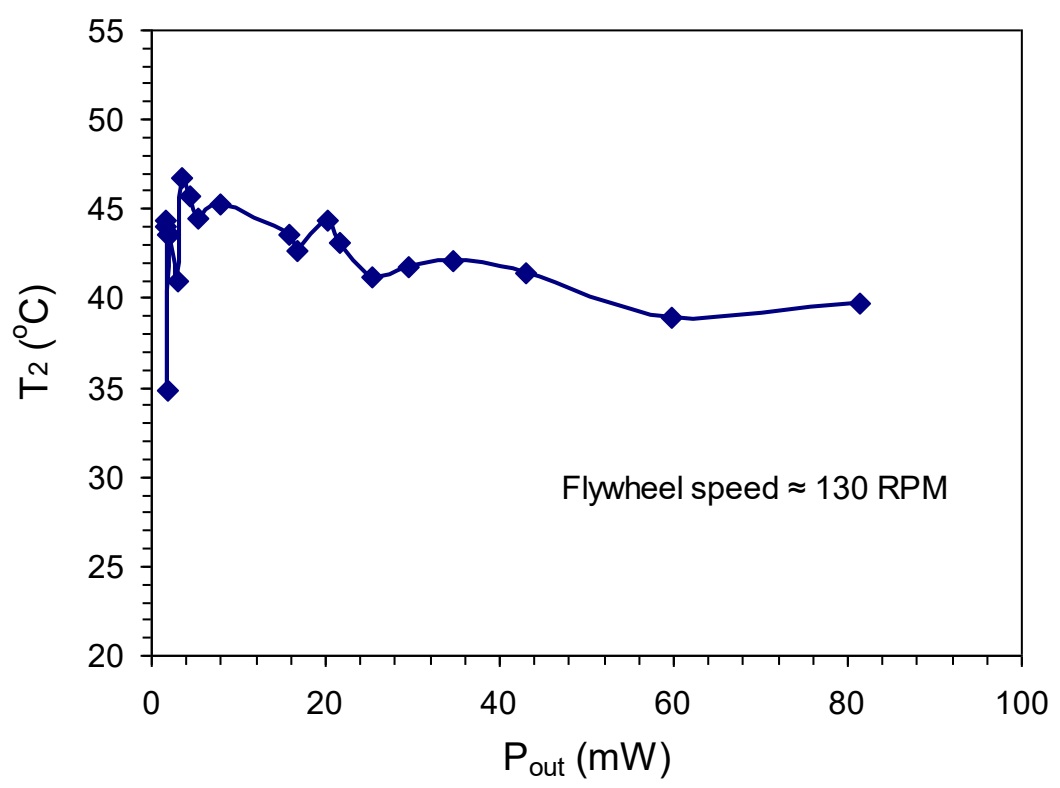

Figure 7: Relation between the output power and the cold region temperature $\left(T_{2}\right)$ for the rotation speed of $\approx 130$ RPM. 


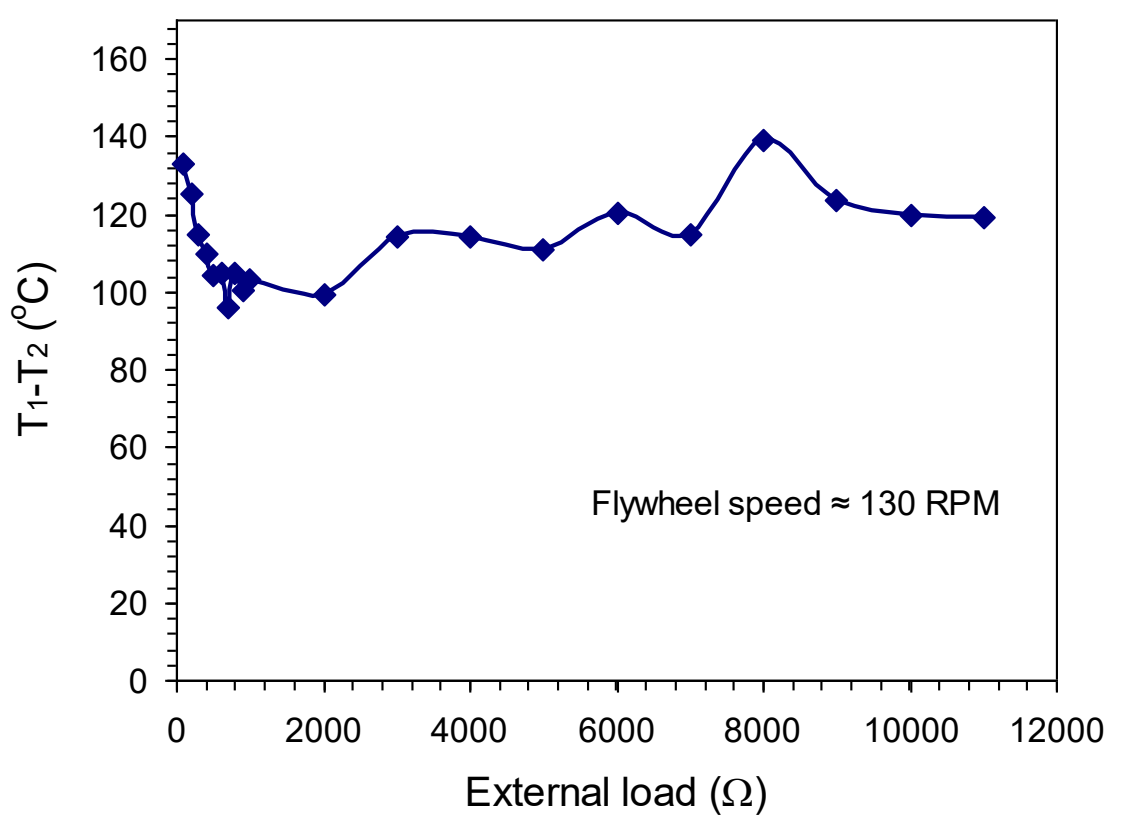

Figure 8: Relation between the external load and the gradient in temperature $\left(T_{1}-T_{2}\right)$ for the rotation speed of $\approx 130$ RPM.

Figure 9 shows the change in the output power and output voltage with increase in the external load. One can see that with the increase in external load resistance the power delivered to the load is decreased while the voltage drop is relatively increased. Despite that the voltage is increased but there is a considerable drop in the electric power. This is ascribed to the larger decrease in the current through the external load compared to the increase in the output voltage. The more decrease at higher resistance acted upon deteriorate the rotation of the flywheel. This change in the rotation of the flywheel can be due to the generation of the electromotive force within the electrical motor connected to the load.

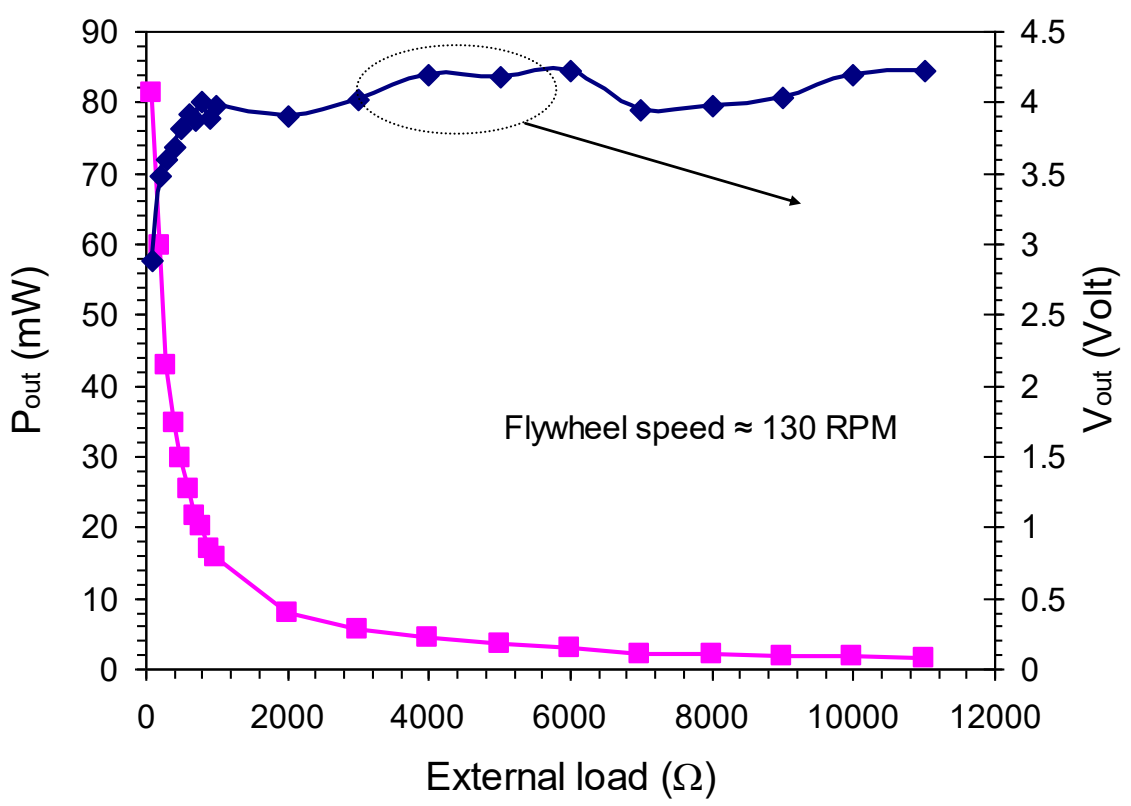

Figure 9: Relation between the external load and the output power and voltage for the rotation speed of $\approx 130 \mathrm{RPM}$. 
Figure 10 shows the change in the output power with increase in the external load for both situations of rotation speed $\approx 122 \mathrm{RPM}$ and130 RPM. Both curves show the same trend of decrease in power with increase of the external load. The reason for this has been previously discussed and analyzed. One more important notice seen here is that the increase in the rotation speed due to the large amount in source burning (alcohol) resulted in the generation of higher output power.

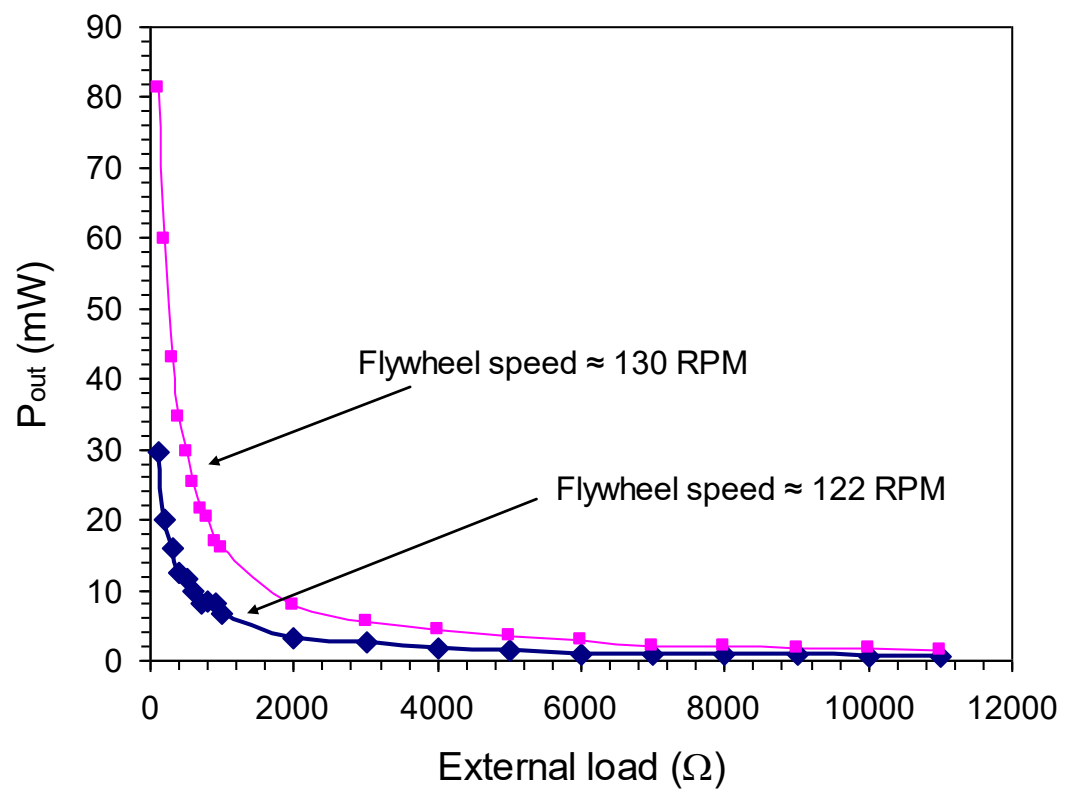

Figure 10: Relation between the external load and the output power and for the rotation speed of $\approx 122$ RPM and130 RPM.

Figure 11 shows the change in the output voltage with increase in the hot region temperature $\left(\mathrm{T}_{1}\right)$, which is the temperature of the hot air to produce a useful expansion for rotating the flywheel and hence generating electricity. It is obvious from the figure that the output voltage is increased at a constant rate for specific range of temperatures, say from $185{ }^{\circ} \mathrm{C}$ to about $240{ }^{\circ} \mathrm{C}$. This has been noticed when the data point on the graph has been fitted with a cubic polynomial to represent the most appropriate curve fitting. It is worth mentioning that at higher temperatures the rate of increase in output voltage is reduced implying that the expansion rate of hot air is getting saturated and the rotating speed of the flywheel reaches to its maximum capability to generate electricity.

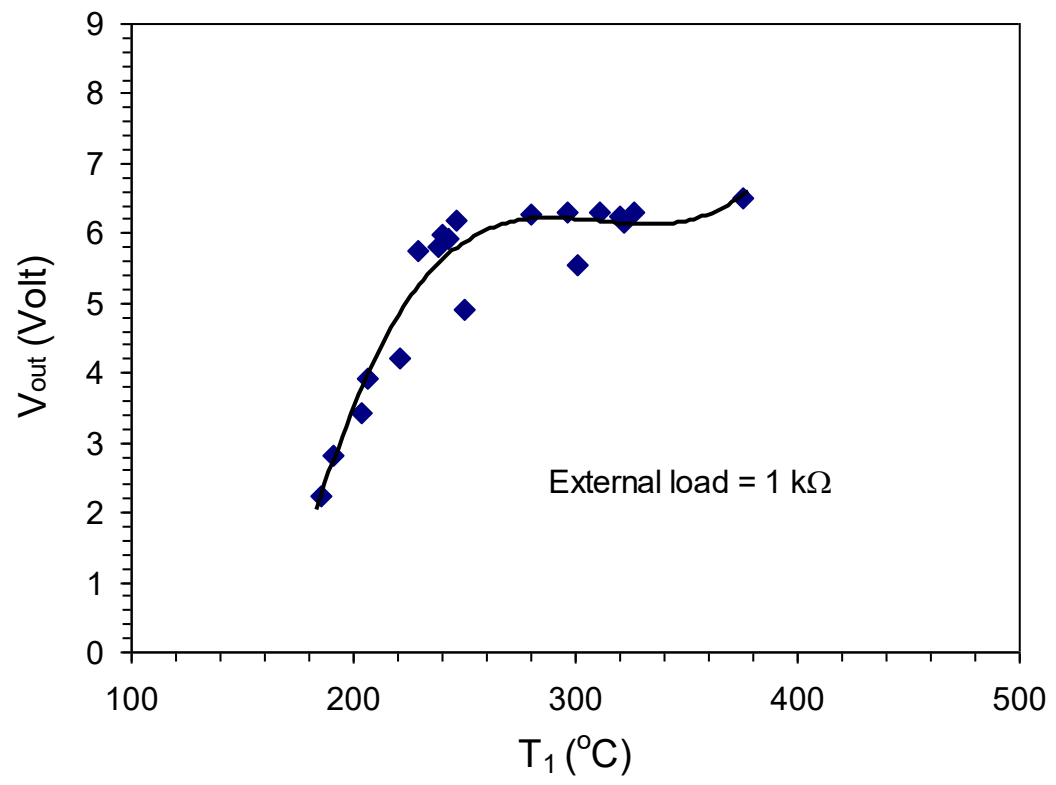

Figure 11: Relation between the output voltage and hot region temperature $\left(T_{1}\right)$ for constant external load $(1 \mathrm{k} \Omega)$. 
Figure 12 shows the change in the load current with increase in the hot region temperature $\left(\mathrm{T}_{1}\right)$ for a constant external load of $1 \mathrm{k} \Omega$. It is obvious from the figure that the output current is increased at a constant rate for specific range of temperatures, say from $185{ }^{\circ} \mathrm{C}$ to about $240{ }^{\circ} \mathrm{C}$. This has been noticed when the data point on the graph has been fitted with a cubic polynomial to represent the most appropriate curve fitting. It is worth mentioning that at higher temperatures the rate of increase in load current is reduced implying that the expansion rate of hot air is getting saturated and the rotating speed of the flywheel reaches to its maximum capability to generate electricity.

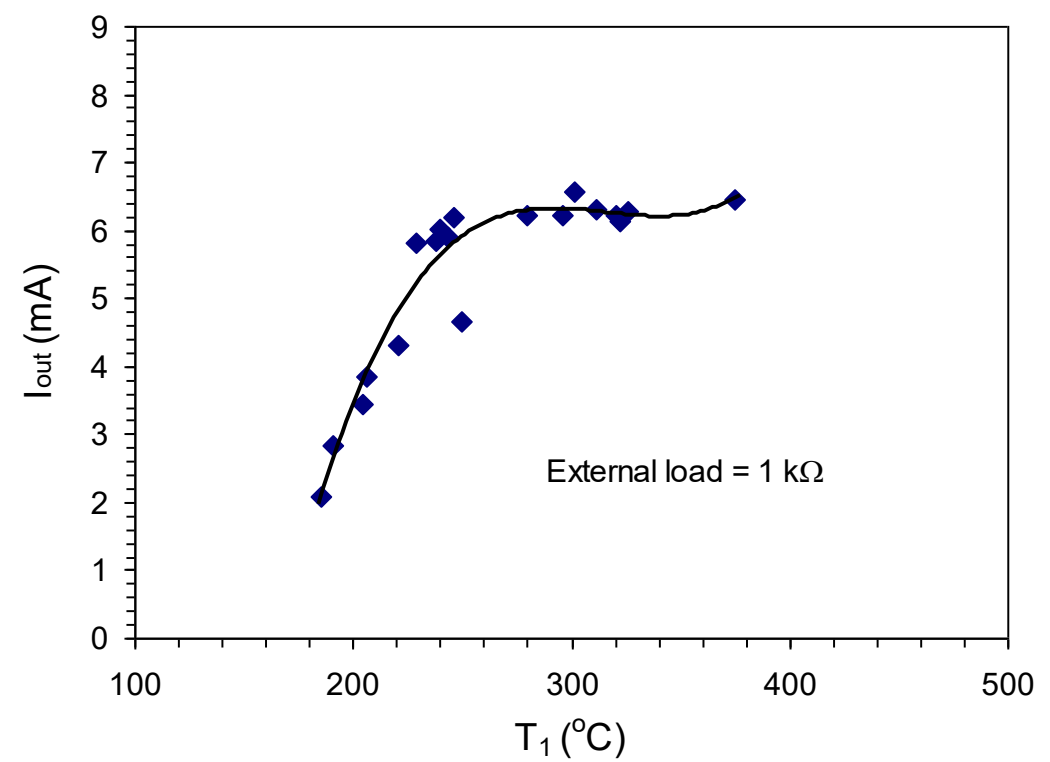

Figure 12: Relation between the load current and hot region temperature $\left(T_{1}\right)$ for constant external load $(1 \mathrm{k} \Omega)$.

Figure 13 shows the change in the output power with increase in the hot region temperature $\left(\mathrm{T}_{1}\right)$ for a constant external load of $1 \mathrm{k} \Omega$. It is obvious from the figure that the output power is sharply increased at a constant rate for specific range of temperatures, say from $185{ }^{\circ} \mathrm{C}$ to about $240{ }^{\circ} \mathrm{C}$. This is referred to as the increase in both voltage and current supplied to the load. The sharp increase was noticed when the data point on the graph has been fitted with a cubic polynomial to represent the most appropriate curve fitting. It is worth mentioning that at higher temperatures the rate of increase in output power is reduced implying that the expansion rate of hot air is getting saturated and the rotating speed of the flywheel reaches to its maximum capability to generate electrical power.

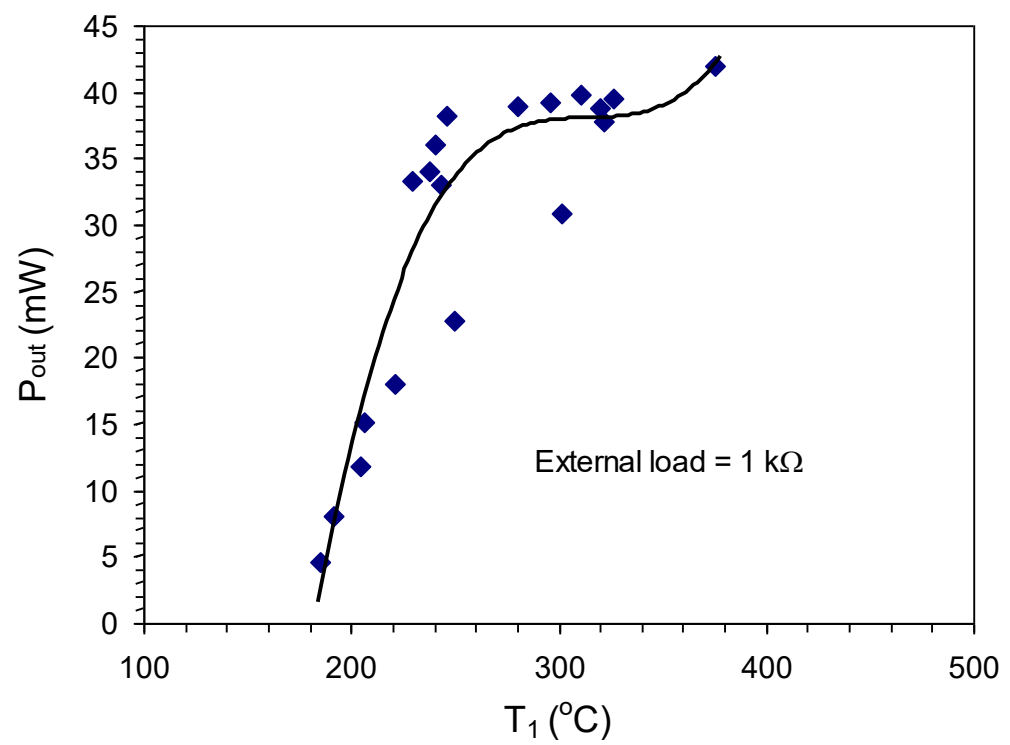

Figure 13: Relation between the output power and hot region temperature $\left(T_{1}\right)$ for constant external load $(1 \mathrm{k} \Omega)$. 


\section{Conclusions}

It was concluded form the results that with increase of the external load there is a less considerable increase in voltage. This has been referred to the variation in the impedance matching between the load and the electric motor. It was observed that by increasing the external load from $100 \Omega$ to about $2000 \Omega$, a rapid decrease in the output power was occurred. However, beyond a specific value of about $2000 \Omega$ the decrease in the electrical power is relatively small. This was ascribed to the decrease in the current flowing through the external load as the more decrease at higher resistance acts upon deteriorate the rotation of the flywheel. It was seen that by increasing the output power, the temperature $T_{2}$ is dropped down more and more. This is a good indication of temperature gradient with respect of the power delivered to the load as the more power transferring means that the cylinders are moving efficiently to make the hot air cooled down easily. The reverse situation is also true to give the agreement that is in accordance with the load matching principle, as at lower output power (high external load) the temperature $T_{2}$ somewhat decreases. The relatively constant temperature gradient at various external load resistances is a right indication to the smooth and stable operation of the thermo electric engine for the production of electrical energy. There may be another sign for which the system was operated in thermally equilibrium with the surrounding. It was obvious from the results of output voltage, current and power with respect to the increase in hot air temperature $\left(T_{1}\right)$ that these physical quantities are increased at a constant rate for specific range of temperatures, say from $185{ }^{\circ} \mathrm{C}$ to about $240{ }^{\circ} \mathrm{C}$. It was worth mentioning that at higher temperatures the rate of increase in output voltage was reduced implying that the expansion rate of hot air is getting saturated and the rotating speed of the flywheel reaches to its maximum capability to generate electricity.

\section{Acknowledgement}

The authors are thankful to the Department of Physics, Koya University, for the administrative support to this work.

\section{Conflict of interests}

The authors declare that there is no conflict of interests regarding the publication of this article.

\section{References}

[1] D.C. Das, A.K. Roy, N. Sinha, International Journal of Electrical Power \& Energy Systems, 43 (2012) 262-279.

[2] S. Bensaid, M. Brignone, A. Ziggiotti, S. Specchia, International Journal of Hydrogen Energy, 37 (2012) 1385-1398.

[3] H. Hun Sik, K. Yun Ho, K. Seo Young, U. Sukkee, H. Jae Min, Thermal and Thermomechanical Phenomena in Electronic Systems (ITherm), 2010 12th IEEE Intersociety Conference on, 2010, pp. 1-7.

[4] K. Makhkamov, V. Trukhov, B. Orunov, A. Korobkov, A. Lejebokov, I. Tursunbaev, E. Orda, V. Chuvichkin, G. Yudin, E. Muhamediev, D.B. Ingham, Energy Conversion Engineering Conference and Exhibit, 2000. (IECEC) 35th Intersociety, 2000, pp. 723-733 vol.722.

[5] C.-L. Chen, C.-E. Ho, H.-T. Yau, Energies, 5 (2012) 3573.

[6] K. Alanne, J. Paatero, I. Beausoleil-Morrison, International Journal of Energy Research, 36 (2012) 218-230.

[7] P.A. Pilavachi, Applied Thermal Engineering, 22 (2002) 2003-2014. 
[8] M. Zamani, G.H. Riahy, N. Abdolghani, M.H. Zamani, G. Shahgholian, Clean Electrical Power (ICCEP), 2011 International Conference on, 2011, pp. 709-714.

[9] G. Lv, H. Wang, W. Ma, C. Yu, Computer Distributed Control and Intelligent Environmental Monitoring (CDCIEM), 2011 International Conference on, 2011, pp. 180-184.

[10] J.E. Noble, G.A. Lehmann, S.G. Emigh, Energy Conversion Engineering Conference, 1990. IECEC-90. Proceedings of the 25th Intersociety, 1990, pp. 281-291.

[11] C.G. Nakis, (2004).

[12] M.A. White, S. Qiu, J.E. Augenblick, AIP Conference Proceedings, 504 (2000) 1266-1271.

[13] https://www.3bscientific.com/stirling-engine-g,p_868_657.html 